\title{
Spermatozoal Fractalkine Signaling Pathway Is Upregulated in Subclinical Varicocele Patients with Normal Seminogram and Low-Level Leucospermia
}

\author{
Salwa M. Abo El-khair, ${ }^{1}$ Mohammad A. Gaballah, ${ }^{2}$ Mamdouh M. Abdel-Gawad, ${ }^{3}$ \\ Sherif Refaat M. Ismail, ${ }^{2}$ and Ayman Z. Elsamanoudy ${ }^{1,4}$ \\ ${ }^{1}$ Department of Medical Biochemistry and Molecular Biology, Faculty of Medicine, Mansoura University, Mansoura, Egypt \\ ${ }^{2}$ Department of Dermatology, Andrology \& STDs, Faculty of Medicine, Mansoura University, Mansoura, Egypt \\ ${ }^{3}$ Department of Dermatology and Andrology, Faculty of Medicine, Port Said University, Port Said, Egypt \\ ${ }^{4}$ Department of Clinical Biochemistry, Faculty of Medicine, King Abdulaziz University, Jeddah, Saudi Arabia
}

Correspondence should be addressed to Mohammad A. Gaballah; mohali212@yahoo.com

Received 5 August 2017; Accepted 5 November 2017; Published 21 December 2017

Academic Editor: Miroslav Djordjevic

Copyright (c) 2017 Salwa M. Abo El-khair et al. This is an open access article distributed under the Creative Commons Attribution License, which permits unrestricted use, distribution, and reproduction in any medium, provided the original work is properly cited.

\begin{abstract}
Background. Fractalkine is produced in seminal plasma in small amounts and correlates with sperm motility. Purpose. To investigate the possible effect of low-level leucospermia on spermatozoa oxidative stress and sDNA fragmentation in patients with subclinical varicocele and apparently normal seminogram, and also to study the role of spermatozoal fractalkine and its receptor (CX3CR1) gene expression as a marker of spermatozoa inflammatory response. Methods. This study included 80 patients with subclinical varicocele (45 fertile and 35 infertile) and 45 age-matched fertile volunteers. In semen samples, fractalkine and CX3CR1 gene expression were investigated by qRT-PCR. Moreover, seminal plasma malondialdehyde (MDA) and total antioxidant capacity (TAC) were measured. Results. There are significant decrease in semen quality and significant increase in seminal leucocytes count in subclinical varicocele. Our results show a significant increase in MDA and TAC levels, DNA fragmentation, and expression levels of fractalkine and its receptor (CX3CR1) in subclinical varicocele groups. Conclusion. Subclinical varicocele induces seminal and spermatozoal subclinical inflammatory response in the form of low-level leucospermia and increased mRNA expression of the fractalkine signaling pathway, leading to increased spermatozoal ROS production, oxidative stress, and DNA fragmentation. These could cooperate in the pathogenesis of delayed fertility in males with subclinical varicocele.
\end{abstract}

\section{Introduction}

Subclinical varicocele is a condition in which varicose veins from the pampiniform plexus cannot be diagnosed by physical examination but need adjunctive diagnostic methods such as Doppler examination, color Doppler ultrasound, scrotal thermography, or venography [1]. Several studies have been conducted to explain the pathophysiology of testicular dysfunction occurring with varicocele. The exact mechanism of infertility caused by varicocele is not completely understood $[2,3]$.

Many hypotheses were postulated and investigated how varicocele could exert a harmful effect on spermatogenesis.
These included semen oxidative stress state $[4,5]$, alterations in spermatozoa DNA integrity and mitochondrial activity [6]. Also, varicocele could decrease the testicular blood flow and renewal with a consequent accumulation of genotoxic substances [7].

Sperm DNA integrity is considered an indicator of normal spermatogenesis and fertility potential in males [8]. Damage of sperm DNA in patients with varicocele is correlated with levels of ROS production as well as varicocele degree [9]. Leucocytes (polymorphonuclear neutrophils and macrophages) have an important effect on male fertility as they are implicated in reactive oxygen species (ROS) production [10]. 
The WHO threshold for leucospermia was previously determined by $1.0 \times 10^{6} \mathrm{WBC} / \mathrm{mL}$ or more [11]. Leucocyte count less than $1.0 \times 10^{6} \mathrm{WBC} / \mathrm{mL}$ (low-level leucospermia) has a significant spermatozaoal damage effect in the form of decrease of motility and DNA integrity [12]. In addition, abnormality of sperm morphology at level of leucospermia as low as $0.5 \times 10^{6} \mathrm{WBC} / \mathrm{mL}$ is reported [10]. Moreover, it is reported that low-level leucospermia is associated with increased seminal level of cytokines (IL-6 and IL-8) which could indicate and prove subclinical inflammation [13].

Fractalkine (CX3CL1) is the solitary member of the CX3C chemokine subfamily [14]. It exists in two forms: the membraneanchored protein and the soluble form. The former is expressed in inflammatory endothelium and functions as an adhesion protein mediating the monocyte and $\mathrm{T}$ cell retention in inflamed tissue, while the soluble form is responsible for inducing chemotaxis. Chemotaxis and adhesion are mediated by the G protein-coupled receptor CX3CR1. Through both chemotactic and adhesive properties, CX3CL1 might have an important role in inflammation, and consequently, CX3CL1/CX3CR1 is involved in pathogenesis of various inflammatory disorders [15].

Fractalkine is produced in seminal plasma in small amounts and correlates with sperm motility [16]. Moreover, chemotaxis and thermotaxis of the sperm have been investigated previously in many studies $[17,18]$. Zhang et al. [19] detected CX3CR1 mRNA and protein in spermatozoa, indicating that fractalkine may play a role in regulating sperm chemotaxis and maintaining its motility.

However, until now, to the best of our knowledge, no reported studies about spermatozoa fractalkine gene expression are published in spite of presence of data about its receptors.

So, in this work we aim at investigating the possible effect of low-level leucospermia on spermatozoa oxidative stress as well as sDNA fragmentation in patients with subclinical varicocele and apparently normal seminogram. Also, we aim at detecting the role of fractalkine and its receptors at the level of spermatozoal mRNA gene expression as a marker of spermatozoa inflammatory response in such patients.

\section{Materials and Methods}

2.1. Subjects Selection. The study is carried out on 125 participants: 80 individuals who were already diagnosed as patients with subclinical varicocele (45 fertile and 35 infertile) and 45 age-matched fertile volunteers with no clinical or sonographic signs of varicocele as a control group. All subjects gave written informed consent. All work was conducted in accordance with the Declaration of Helsinki (1964), and an approval was obtained from the Institutional Review Board (IRB) of Mansoura Faculty of Medicine.

The included infertile subjects have normal seminogram according to WHO [11]. They had attended the clinics of Andrology and Vascular Surgery Units, Mansoura University Hospital, from January 2014 to April 2015. They are married for more than one year with failed conception and unprotected regular intercourse. We excluded infertile couples that had female factors. An infertility sheet was obtained. Complete general and local genital examination was performed. Selected subjects had normal serum hormonal levels (FSH, LH, prolactin, T3, T4, TSH, estradiol and total and free testosterone). Scrotal color Doppler ultrasound was performed to confirm clinically detected varicocele and to diagnose subclinical one.

This research excluded any patient with semen abnormality, leucospermia $\left(>1 \times 10^{6} / \mathrm{ml}\right)$, or had infertility risk factor (gonadal toxins, cigarette smoking, use recreational drugs, alcohol intake, urogenital infection, clinically detected varicocele, undescended or small-sized testes, and cryptorchidism). Also, patients with any chronic disease (heart, kidney, or liver disease), endocrine disorder, acute or chronic inflammatory disease, or long-term medications (e.g., corticosteroids) were excluded.

Subclinical varicocele was diagnosed and graded by scrotal color Doppler ultrasonography according to classification of Sarteschi et al. [20]:

Grade 1: venous reflux at the emergence of the scrotal vein only during the Valsalva maneuver; hypertrophy of the venous wall without stasis.

Grade 2: supratesticular reflux only during the Valsalva maneuver; venous stasis without varicosities.

Grade 3: peritesticular reflux during the Valsalva maneuver; overt varicocele with early-stage varices of the cremasteric vein.

Grade 4: spontaneous basal reflux that increases during the Valsalva maneuver, possible testicular hypotrophy, overt varicocele, varicosities in the pampiniform plexus.

Grade 5: spontaneous basal reflux that does not increase during the Valsalva maneuver, testicular hypotrophy, overt varicocele, varicosities in the pampiniform plexus.

The scrotal color Doppler ultrasonography maneuver was done according to the American Institute of Ultrasound in Medicine (AIUM) [21] and Italian Society for Vascular Investigation (SIDV-GIUV) [22].

2.2. Samples Collection. Semen samples were collected from the subjects attending the Infertility Clinic of Andrology Unit, Mansoura University Hospital. After sexual abstinence (3-5 days), semen samples were collected by masturbation.

2.3. Standard Semen Analysis. Seminal fluid was left for 1 hour at $37^{\circ} \mathrm{C}$ for liquefaction. Then, it was transferred to a test tube, and ejaculation volume was recorded. Sperms count and motility (total and progressive) were assessed with the motility/concentration module of the computer-assisted semen analysis (CASA) system using MiraLab-Egypt (Mira 9000 sperm Analyzer CASA software).

Morphology was investigated by smear preparation and sperm Mac stain method (Fertipro, Belgium) recommended by WHO [11]. Leucocytes count was identified by peroxidase staining technique as described by Politch and colleagues [23], which was firstly described by Endtz [24]. Viability was 
evaluated by Eosin Y staining with 100 cell score for stain uptake (dead cell) or exclusion (live cell) [25]. After semen sample liquefaction, seminal plasma was collected by centrifugation at $7000 \mathrm{rpm}$ and stored as aliquots at $-30^{\circ} \mathrm{C}$ until used for estimating 8-hydroxy-2'-deoxyguanosine (8-OHdG), malondialdehyde (MDA), and total antioxidant capacity (TAC).

2.4. RNA Extraction. One milliliter semen sample, after liquefaction, was added into tube with $2 \mathrm{ml}$ RNAlater reagent (Sigma). Then, cells were pelleted by centrifugation. Following the manufacturer's instructions, total RNA was extracted from the sperm pellet using TriFast TM reagent (PeqLab. Biotechnologie GmbH, Carl-Thiersch Str. 2B 91052 Erlangen, Germany, Cat. No. 30-2010). Remaining DNAs were eliminated by digestion with DNase I (Sigma). Extracted RNA concentration and purity were determined by NanoDrop ${ }^{\mathrm{TM}} 2000$ Spectrophotometer (Thermo Scientific, USA). Confirmation of the extracted RNA purity was done by formaldehyde agarose gel electrophoresis (2\%) and ethidium bromide staining, to present 2 sharp bands (28S and $18 \mathrm{~S}$ rRNA).

2.5. Fractalkine and CX3CR1 Genes Expression by Real-Time Quantitative RT-PCR. According to manufacturer's instructions, reverse transcription (RT) of the isolated RNA was carried out using Maxima First Strand cDNA Synthesis Kit for qRT-PCR (ThermoScientific, USA, cat No \#K1641). The synthesized $\mathrm{cDNA}$ was stored at $-20^{\circ} \mathrm{C}$ until use for qRT-PCR.

Primers for gene-specific qRT-PCR (purchased from Oligo $^{\mathrm{TM}}$ Macrogen) were designed using the Primer3 software (v. 0.4.0) (http://frodo.wi.mit.edu/) to amplify human fractalkine (CX3CL1) with the following sequences: $5^{\prime}$-CTGCTGCCCTAACTCGAAAT- $3^{\prime}$ (forward) and $5^{\prime}$-AGGACCACAGACTCGTCCAT-3' (reverse) (PCR product: $103 \mathrm{bp}$ ), CX3CR1-specific primers were $5^{\prime}$-CACAAAGGAGCAGGCATGGAAG-3' (forward) and 5'-CAGGTTCTCTGTAGACACAAGGC-3' (reverse) (CX3CR1-product: $119 \mathrm{bp}$ ), while for $\beta$-actin, used as internal control (184 bp), 5' - AGAGCTACGAGCTGCCTGAC-3' (forward) and 5' - AGCACTGTGTTGGCGTACAG$3^{\prime}$ (reverse).

The qRT-PCR reactions $(25 \mu \mathrm{L})$ were carried out, in duplicates, including $12.5 \mu \mathrm{L}$ Power Sybr ${ }^{\circledR}$ Green PCR Master Mix reaction buffer (Applied Biosystem), $10 \mathrm{pmol}$ of forward and reverse gene-specific primers, and $2 \mu \mathrm{L}$ cDNA. The reaction cycling was 35 cycles (held for $15 \mathrm{sec}$ at $95^{\circ} \mathrm{C}$ and for $30 \mathrm{sec}$ at $60^{\circ} \mathrm{C}$ ) after an initial one cycle at $95^{\circ} \mathrm{C}$ for $10 \mathrm{~min}$. CT values (cycle threshold) were recorded. Melting curve analysis and 2\% agarose gel electrophoresis were carried out to confirm PCR product specificity. No template negative control reaction was run in each experiment.

Relative quantification for fractalkine and CX3CR1 gene expression in semen samples was determined by the comparative $\Delta \Delta \mathrm{CT}$ method. $\beta$ actin was used as an internal control gene. For the overall change, calculation of $\Delta \Delta \mathrm{CT}$ between cases and control samples was performed and linearized by $2^{-\Delta \Delta \mathrm{CT}}$ formula.
2.6. DNA Fragmentation Analysis. DNA fragmentation analysis was done by agarose gel electrophoresis [26]. Spermatozoa were collected after centrifugation, and DNA fragmentation was assessed by Enhanced Apoptotic DNA Ladder Detection kit (BioVision Research Products 980 Linda Vista Avenue, Mountain View, CA 94043, USA). In a $1.5 \mathrm{ml}$ microcentrifuge tube, sperm pellet $5-10 \times 10^{5}$ cells was washed with phosphate buffer saline, and the pellet was centrifuged for $5 \mathrm{~min}$ at $500 \mathrm{~g}$. Supernatant was removed, and the cells were then lysed with $35 \mu \mathrm{l}$ Tris EDTA lysis buffer. $5 \mu \mathrm{l}$ of enzyme A reagent was added and incubated at $37^{\circ} \mathrm{C}$ for $10 \mathrm{~min}$. Then, $5 \mu \mathrm{l}$ of enzyme $\mathrm{B}$ reagent was added and incubated at $50^{\circ} \mathrm{C}$ for $30 \mathrm{~min}$. Ammonium acetate $(5 \mu \mathrm{l})$ and isopropanol $(50 \mu \mathrm{l})$ were added and mixed well. Washing of DNA pellet with $0.5 \mathrm{ml}$ ethanol $70 \%$ was done and air-dried. Finally, dissolving DNA pellet in $20 \mu \mathrm{l}$ DNA suspension buffer was performed. The sample was loaded into a $1.8 \%$ agarose gel. The gel was stained by staining buffer (provided by the kit) with shaking gently for 30 minutes. DNA ladder was visualized with UV Transilluminator (Model TUV-20, OWI Scientific, Inc., 800 242-5560, France) and photographed.

2.7. Assay of Oxidative Stress Markers. Seminal plasma MDA [27] and TAC [28] were measured by colorimetric method using commercially available Kit (Cayman Chemical, Ann Arbor, MI, USA). Quantitative determination of seminal plasma 8-OHdG level was performed by Abnova 8-OHdG ELISA kit (Catalog number KA0444). The samples absorbance was determined using plate ELISA reader (Tecan, Sunrise Absorbance reader, Austria) at a $450 \mathrm{~nm}$ wave length.

2.8. Statistical Analysis. Data were tabulated, coded, and analyzed with the computer program SPSS (Statistical Package for Social Science) version 17.0. Descriptive statistics were presented as mean and standard deviation (mean $\pm \mathrm{SD}$ ). For statistical comparison, ANOVA (analysis of variance) test (for $>2$ groups of numerical parametric data) followed by post hoc was used. Pearson correlation coefficient test was used for different parameter correlation. The sensitivity and specificity were examined at different cutoff points using ROC curve analysis to determine the best cutoff point as well as the diagnostic power of each test. $P$ value of $<0.05$ was considered statistically significant.

\section{Results and Discussion}

3.1. Results. The present study included 125 subjects with a mean age of $30.7 \pm 11.3$ years. The subjects were divided into 3 groups: 45 healthy subjects as controls and 80 patients with subclinical varicocele ( 45 fertile and 35 infertile). The subclinical varicocele patients were grade I or II by color Doppler ultrasound.

There are significant decrease in the quality of semen (concentration, normal morphology, motility, and vitality) and significant increase in the leucocytes count in the two subclinical varicocele groups in comparison to the control 
TABLE 1: Semen parameters of all studied groups.

\begin{tabular}{lccc}
\hline & Control & Fertile-subclinical varicocele & Infertile-subclinical varicocele \\
\hline Number of cases & 45 & 45 & 35 \\
Volume (ml) & $3.61 \pm 0.73$ & $4.26 \pm 1.14^{\mathrm{a}}$ & $5.02 \pm 1.02^{\mathrm{b}, \mathrm{c}}$ \\
Concentration $\left(10^{6} / \mathrm{ml}\right)$ & $117.11 \pm 30.85$ & $98.23 \pm 17.09^{\mathrm{a}}$ & $71.22 \pm 19.04^{\mathrm{b}, \mathrm{c}}$ \\
Normal morphology $(\%)$ & $54.28 \pm 18.29$ & $37.09 \pm 12.60^{\mathrm{a}}$ & $16.49 \pm 4.20^{\mathrm{b}, \mathrm{c}}$ \\
$\%$ Motility (PR) & $69.62 \pm 13.91$ & $50.50 \pm 9.41^{\mathrm{a}}$ & $33.58 \pm 8.01^{\mathrm{b}, \mathrm{c}}$ \\
Vitality $(\%)$ & $56.51 \pm 11.41$ & $44.49 \pm 10.11^{\mathrm{a}}$ & $30.44 \pm 8.07^{\mathrm{b}, \mathrm{c}}$ \\
WBCs $\left(10^{6} / \mathrm{ml}\right)$ & $0.26 \pm 0.08$ & $0.57 \pm 0.14^{\mathrm{a}}$ & $0.75 \pm 0.13^{\mathrm{b}, \mathrm{c}}$ \\
\hline
\end{tabular}

Data are represented in the form of mean $\pm \mathrm{SD}$; ${ }^{\mathrm{a}}$ significance between control group and fertile-subclinical varicocele group; ${ }^{\mathrm{b}}$ significance between control group and infertile-subclinical varicocele group; 'significance between fertile-subclinical varicocele group and infertile-subclinical varicocele group; PR: progressive motility.

group. Also, there are significant decrease in the quality of semen and significant increase in the leucocytes count in the infertile group in comparison to the fertile group, but all parameters are still within normal values according to the normal reference ranges of WHO (2010) (Table 1).

Our results show that there are significant increases in MDA and 8-OHdG levels in subclinical varicocele groups in comparison to control and in the infertile group in comparison to the fertile group (Figures 1(a)-1(c)). Also, there is a significant decrease in TAC of subclinical varicocele groups in comparison to control and in the infertile group in comparison to the fertile group (Figure 1(b)).

There is a significant increase in the DNA fragmentation in subclinical varicocele groups in comparison to control and in the infertile group in comparison to the fertile group (Figure 1(d)). The expression levels of fractalkine and its receptor (CX3CR1) are significantly increased in subclinical varicocele groups in comparison to control and in the infertile group in comparison to the fertile group (Figures 1(e) and $1(\mathrm{f})$ ).

Moreover, results of the present study (Figure 2) show a strong positive correlation between fractalkine expression and MDA level, 8-OHdG level, DNA fragmentation, and seminal leucocytes counts. On the other hand, it shows a negative correlation with TAC.

The effectiveness of fractalkine expression and 8-OHdG in discriminating fertile from infertile men with different clinical diagnoses was studied by generating receiver operating characteristic (ROC) curves (Figure 3). The fractalkine expression level sensitivity was 92.5, and specificity was 91.1 (AUC $=95.0 \%$, cutoff $=1.427)$ in discriminating controls from infertile patients. The 8 -OHdG expression level sensitivity was only 87.5 , and specificity was 91.1 (AUC $=93.8 \%$, cutoff $=16.62)$ in discriminating controls from infertile patients. When setting the cutoff to 0.519 , the seminal leucocytes count sensitivity was only 80.0 , and specificity was $100.0($ AUC $=93.8 \%)$ (Table 2$)$.

3.2. Discussion. Testicular dysfunctions that are associated with varicocele include elevated intratesticular temperature, developing testicular hypoxia, testicular gonadotoxins, and seminal of oxidants accumulation as well as evident production of anti-sperm antibodies. The documented pathophysiologic effects of varicocele could be suppressed activity of testicular DNA polymerase enzyme, induction of testicular apoptosis, and oxidative stress. Moreover, Sertoli and Leydig cell dysfunction and hormonal disorders were also reported [29].

The first objective of our study is to investigate the possible causative or associated relationship of low-level leucospermia and spermatozoa oxidative stress as well as sDNA fragmentation in patients with subclinical varicocele and apparently normal seminogram.

It is evident in the current study that subclinical varicocele is associated with spermatozoa oxidative stress which is presented by increased seminal plasma MDA and 8OHdG with a significant increase in the percentage of sDNA fragmentation. On the other hand, there is a marked decrease in seminal TAC. The seminogram parameters also show a significant decrease in contrast to the controls in spite of the fact that it is still within normal level according to WHO [11] criteria. All of these findings are significantly more deteriorated in the infertile group of individuals when compared to the fertile peers.

The nonspecific seminal stress pattern in men with varicocele (either clinical or subclinical like our target group) is previously reported by Zümrütbaş et al. [30], documented by Pathak et al. [29] and confirmed in the current study by our mentioned findings. Moreover, spermatozoa oxidative stress is a dominant recognized molecular aberration in males with any degree of varicocele [31]. Spermatozoal oxidative stress could play an important role in pathogenesis of delayed fertility in such individuals [32].

Leucocytes and abnormal sperms are considered major sources of ROS in semen. Both are prominent features of varicocele $[29,31]$. These coincide with our results.

Spermatozoa membrane and nuclear DNA damage caused by increased ROS with defective antioxidant defect could play a role in development of poor sperm quality including motility and fertilizing ability [33, 34]. Sperm mitochondrial and nuclear DNA are potential targets of attack by ROS [35] which usually progress to sperm apoptotic events that are completed in the epididymis during sperm maturation and capacitation [32].

Spermatozoa DNA fragmentation is associated with poor sperm function and quality regardless of the semen parameters. In most of the cases, seminogram shows a normal pattern on examination with CASA [36] as in our study but 


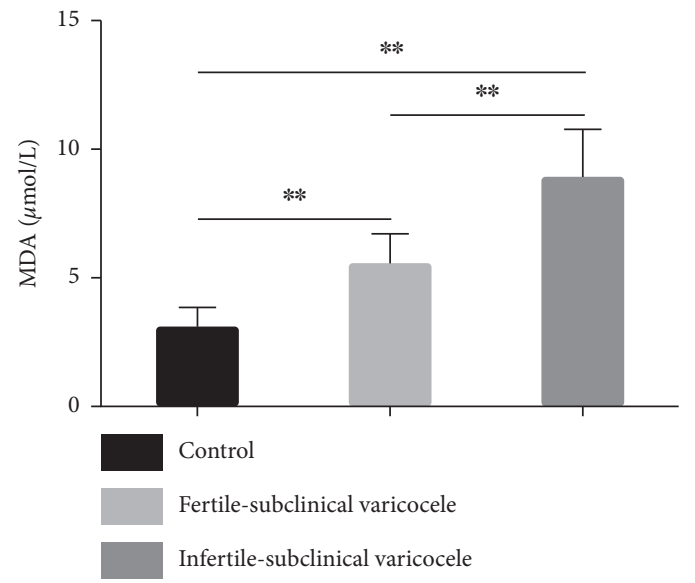

(a)

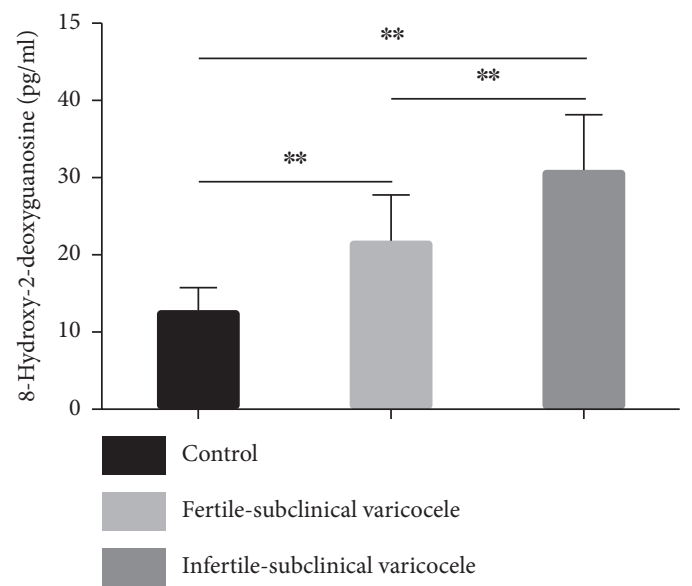

(c)

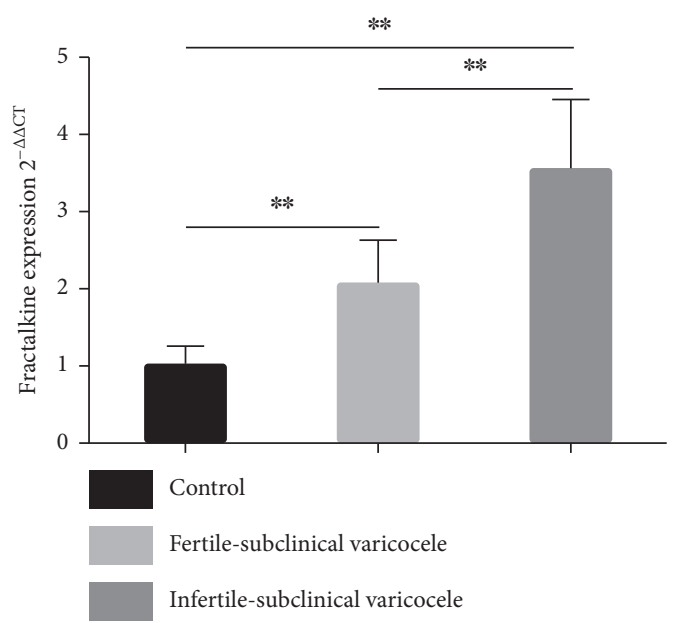

(e)

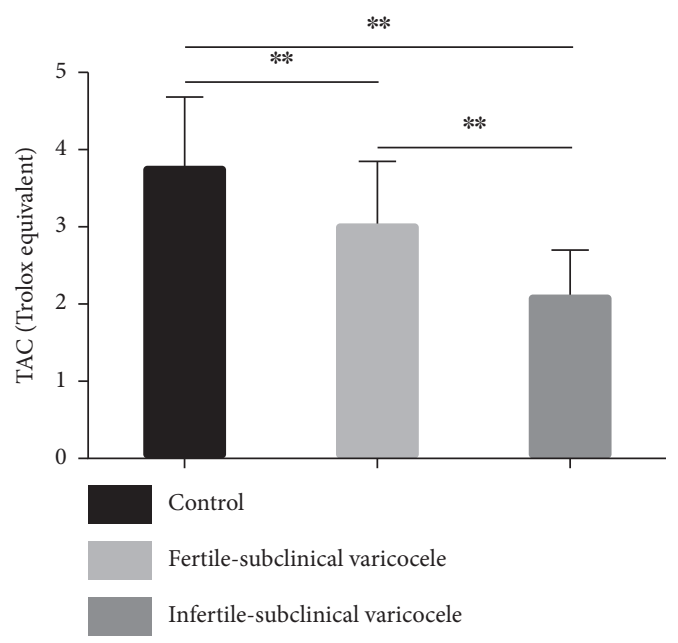

(b)

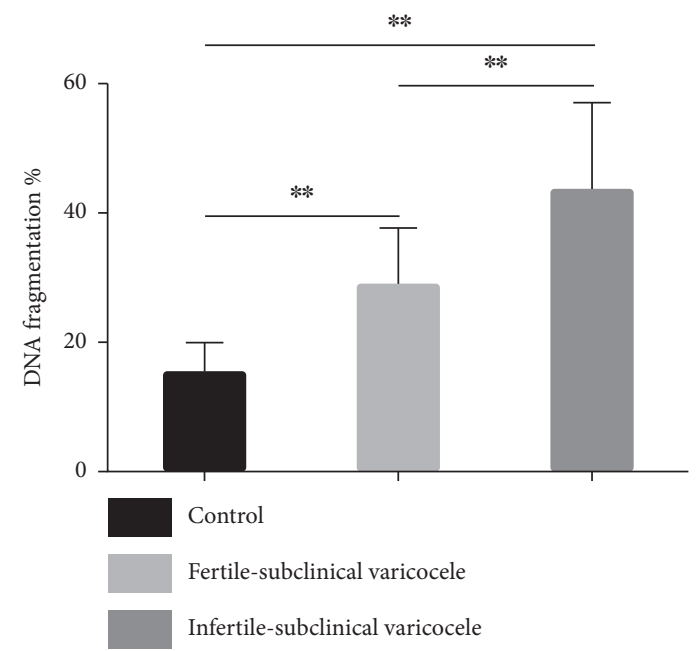

(d)

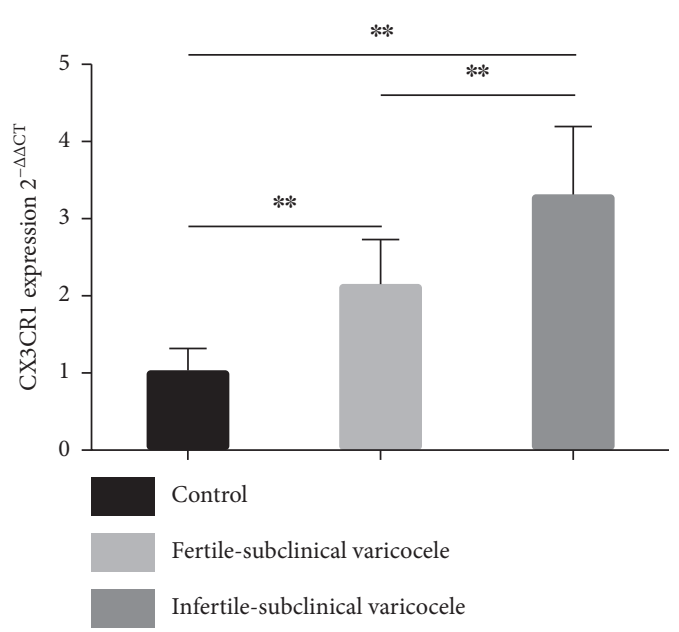

(f)

Figure 1: Oxidative stress state, DNA fragmentation, and fractalkine expression in subclinical varicocele patients. (a) Levels of MDA. (b) TAC. (c) 8-OHdG level. (d) DNA Fragmentation. (e) Fractalkine gene expression. (f) CX3CR1 gene expression. Data are represented in the form of mean \pm SD. ${ }^{*} p<0.05,{ }^{* *} p<0.005,{ }^{* * *} p<0.0005$. 

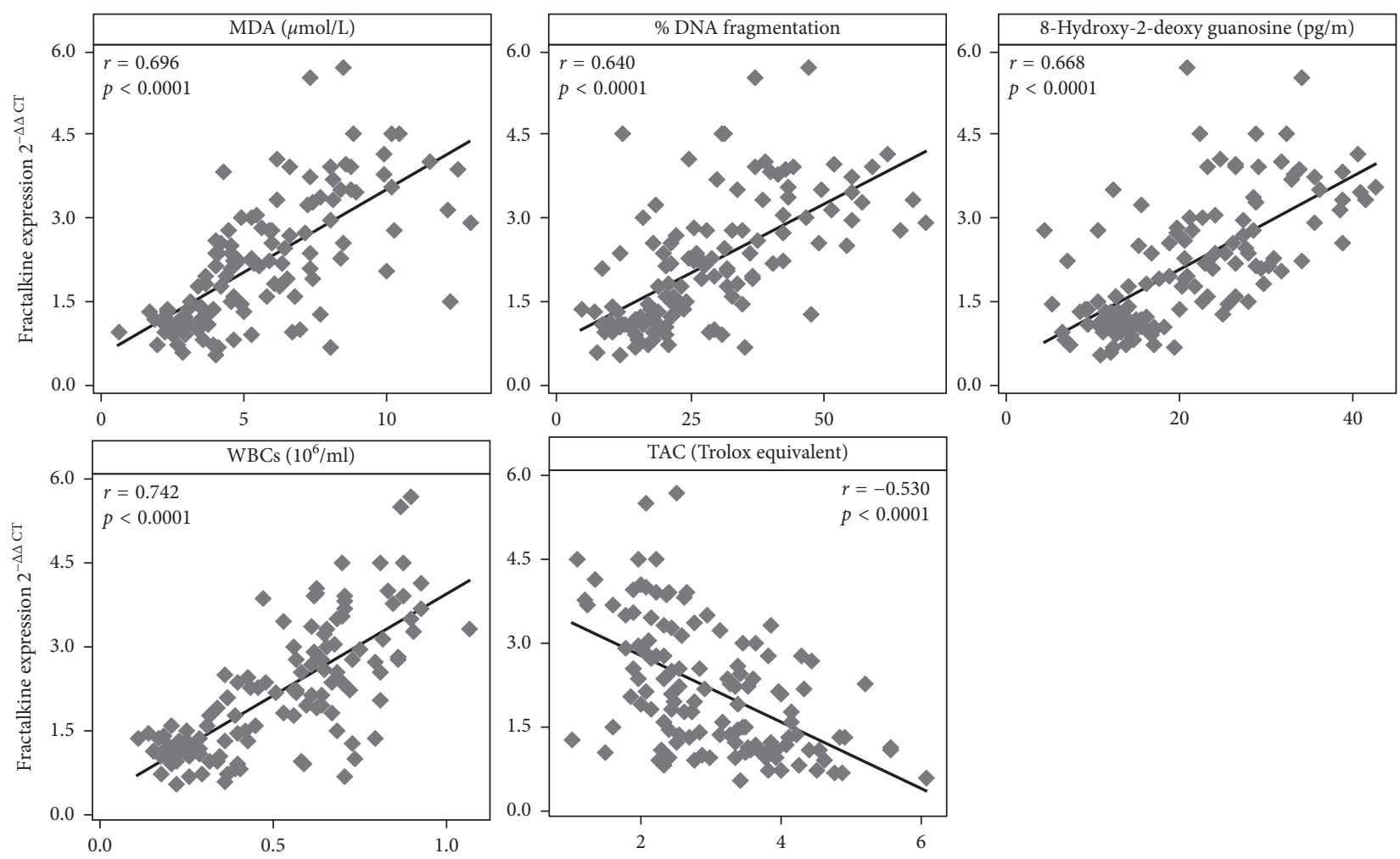

FIgURe 2: Correlation between fractalkine expression and other parameters. $r$ : Pearson's correlation coefficient. $p$ : Probability.

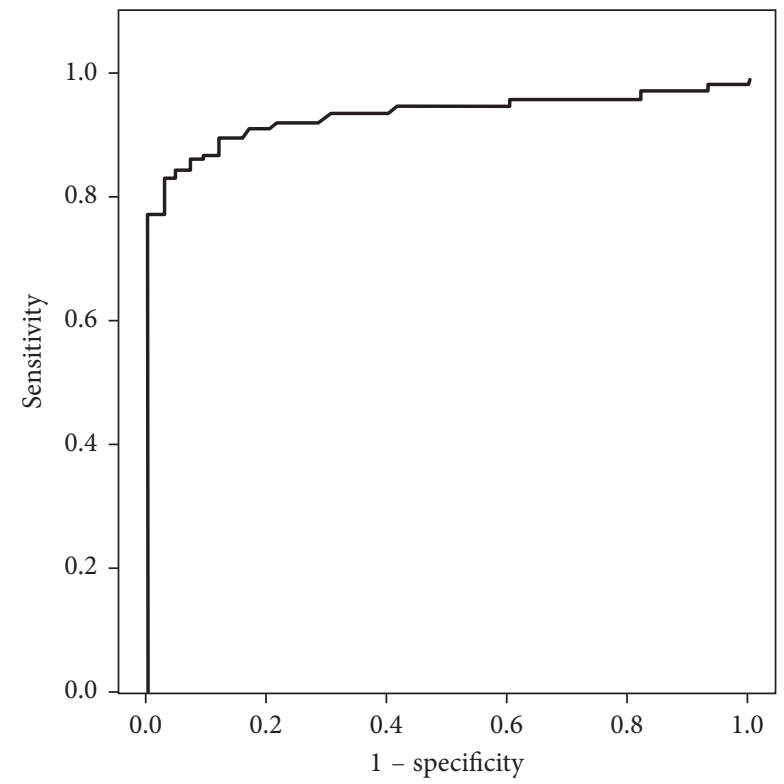

8-Hydroxy-2-deoxyguanosine

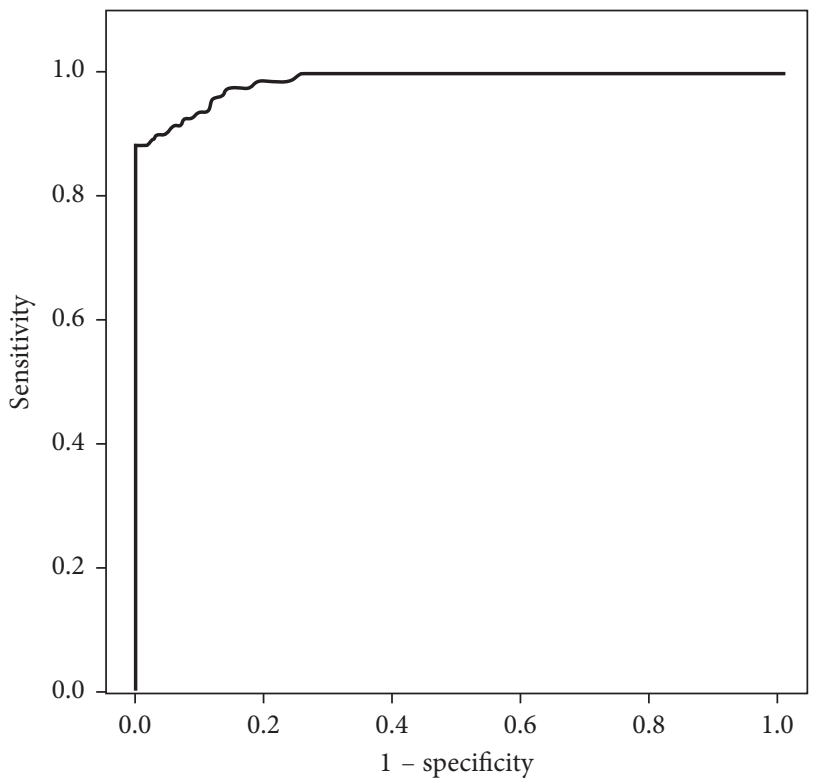

WBCs

Figure 3: ROC curve analysis of 8-hydroxy-2-deoxyguanosine (8-OHdG) and seminal leucocytes count (WBCs).

could be a main cause of delayed fertility in such individuals. So, the current study tested the specificity and sensitivity of 8-OHdG as a reliable sDNA damage marker in our target group. It shows $91.1 \%$ specificity and $87.5 \%$ sensitivity at cutoff level $16.62 \mathrm{pg} / \mathrm{ml}$. It needs further investigation to confirm our result in larger number of subjects.
Also, we tested the specificity and sensitivity of low-level leucospermia as causative pathophysiologic mechanism in our target studied group (subjects with subclinical varicocele either fertile or infertile). ROC curve analysis revealed $100 \%$ specificity and $80.0 \%$ sensitivity at a cutoff level of $0.519 \times 10^{6} / \mathrm{ml}$. The result of the current study supports Agarwal et al. [10]. 
TABLE 2: ROC curve analysis of 8-OHdG and seminal leucocytes count.

\begin{tabular}{|c|c|c|c|c|c|c|c|}
\hline & AUC (CI 95\%) & Cutoff value & Sensitivity \% & Specificity \% & PPV \% & NPV \% & Accuracy \% \\
\hline 8-OHdG & $0.938(0.89-0.98)$ & 16.62 & 87.5 & 91.1 & 94.6 & 80.4 & 88.8 \\
\hline Seminal leucocytes count & $0.988(0.975-1.00)$ & 0.519 & 80.0 & 100.0 & 100.0 & 73.8 & 87.2 \\
\hline
\end{tabular}

AUC: area under the curve, CI: confidence interval, PPV: positive predictive value, NPV: negative predictive value.

They reported a nearly similar result of leucospermia $\left(0.5 \times 10^{6} / \mathrm{ml}\right)$. Both results are much lower than that of WHO criteria of semen analysis [11] that documented $1.0 \times 10^{6} / \mathrm{ml}$ is considered clinically significant and requires treatment. So, we could confirm the link between low levels of leucospermia and ROS generation [37] with its consequent pathological effects [13], especially sperm nuclear DNA fragmentation [38].

Like our study, Agarwal et al. [10] found no significant changes in semen parameters in individuals with low-level leucospermia from nonleucospermic subjects. Yet, ROS levels and the percentage of DNA damage were significantly high in the low-level leucospermia group. This supports that the level of leucospermia lower than the WHO criteria threshold [11] may have an impact on male fertility at the cellular and molecular levels rather than the seminogram parameters and may require treatment.

The concomitant presence of subclinical varicocele, lowlevel leucospermia, and sperm nuclear DNA fragmentation could play an important pathophysiologic mechanism of subfertility predisposition or even affect the male fertility potentials as presented in our study and documented previously by Agarwal et al. [10]. Alshahrani et al. [39] added another factor which is the advancing age. It was reported that all of these factors are associated with low fertilization rate, increased abortion risk, and incidence of diseases in offspring. They are also considered strong predictors of male fertility [39-41].

The five proposed and studied mechanisms of varicoceleinduced delayed male fertility (hypoperfusion leading to hypoxia, heat stress, oxidative stress, hormonal imbalance, and exogenous toxins) still do not provide a full understanding. So, genetic and molecular factors might have a role in clarifying pathogenesis of varicocele-associated infertility $[5,42]$. Consequently, the second objective of our work is to study the role of fractalkine and its receptors at the level of spermatozoal mRNA gene expression as a candidate molecular marker of spermatozoa inflammatory response.

The debate about the role of inflammation in varicocele pathogenesis of male subfertility took a long time of discussion. But it is documented that remarkable increase of ROS levels which can cause an inflammatory response detrimental to testicular tissue. It has been shown that varicocele increased ROS stress in a time-dependent manner. Varicocele-induced inflammation negatively impacted Sertoli cell physiologic function and may induce maturation arrest of spermiogenesis [43].

Many previous studies dealt with many seminal cytokines and inflammatory mediators in case of varicocele as nuclear factor-kappa B (NF- $\kappa$ B) [44], interleukin-1 $\beta$ (IL-1 $\beta$ ) [43], interleukin-6 (IL-6) and interferon-gamma [45], interleukin-37 (IL-37), interleukin-18-binding protein (IL-18BP), IL-18 receptor $\beta$, IL-18 [46], TNF- $\alpha$, IL1 $\alpha$, IL6, Cd45, Cd3g, and Cd3d [47].
The novelty of our study is investigating spermatozoa fractalkine signaling pathway gene expression at the level of mRNA. There are no published data about this issue is documented.

Our results revealed increased spermatozoa mRNA expression of fractalkine and its coupled receptors (CX3CR1) in individuals with subclinical varicocele which is significantly higher in the infertile subgroup when compared to those of the fertile group. Their expression levels are positively correlated with MDA, 8-OHdG, WBCs count, and sperm nuclear DNA fragmentation \% while it is negatively correlated with seminal TAC.

These results could prove their involvement in the pathophysiology of varicocele-induced spermatozoa subclinical inflammation and pathogenesis in male subfertility in such individuals.

The present study could conclude that subclinical varicocele induces seminal and spermatozoal subclinical inflammatory response in the form of low-level leucospermia and increased mRNA expression of the fractalkine signaling pathway. This inflammatory response leads to increased spermatozoal ROS production, oxidative stress, and nuclear DNA fragmentation. All of these interplay mechanisms could cooperate in the pathogenesis of delayed fertility in males with subclinical varicocele.

\section{Conflicts of Interest}

The authors declare that no benefits in any form have been received or will be received from a commercial party related directly or indirectly to the subject of this article. The authors also declare that they have no conflicts of interest in connection with this paper.

\section{References}

[1] A. Pilatz, B. Altinkilic, E. Kohler, M. Marconi, and W. Weidner, "Color Doppler ultrasound imaging in varicoceles: is the venous diameter sufficient for predicting clinical and subclinical varicocele?," World Journal of Urology, vol. 29, no. 5, pp. 645-650, 2011.

[2] V. Ficarra, A. Crestani, G. Novara, and V. Mirone, "Varicocele repair for infertility: what is the evidence?," Current Opinion in Urology, vol. 22, no. 6, pp. 489-494, 2012.

[3] T. C. Kadioglu, E. Aliyev, and M. Celtik, "Microscopic varicocelectomy significantly decreases the sperm DNA fragmentation index in patients with infertility," BioMed Research International, vol. 2014, Article ID 695713, 4 pages, 2014.

[4] A. Agarwal and R. A. Saleh, "Role of oxidants in male infertility: rationale, significance, and treatment," Urologic Clinics of North America, vol. 29, no. 4, pp. 817-827, 2002.

[5] M. M. Sheehan, R. Ramasamy, and D. J. Lamb, "Molecular mechanisms involved in varicocele-associated infertility," 
Journal of Assisted Reproduction and Genetics, vol. 31, no. 5, pp. 521-526, 2014.

[6] K. Li, X. Shang, and Y. Chen, "High-performance liquid chromatographic detection of lipid peroxidation in human seminal plasma and its application to male infertility," Clinica Chimica Acta, vol. 346, no. 2, pp. 199-203, 2004.

[7] R. M. Fariello, J. R. Pariz, D. M. Spaine et al., "Effect of smoking on the functional aspects of sperm and seminal plasma protein profiles in patients with varicocele," Human Reproduction, vol. 27, no. 11, pp. 3140-3149, 2012.

[8] R. Smith, H. Kaune, D. Parodi et al., "Increased sperm DNA damage in patients with varicocele: relationship with seminal oxidative stress," Human Reproduction, vol. 21, no. 4, pp. 986-993, 2006.

[9] C. G. Blumer, R. M. Fariello, A. E. Restelli, D. M. Spaine, R. P. Bertolla, and A. P. Cedenho, "Sperm nuclear DNA fragmentation and mitochondrial activity in men with varicocele," Fertility and Sterility, vol. 90, no. 5, pp. 1716-1722, 2008.

[10] A. Agarwal, A. Mulgund, S. Alshahrani et al., "Reactive oxygen species and sperm DNA damage in infertile men presenting with low level leukocytospermia," Reproductive Biology and Endocrinology, vol. 12, no. 1, p. 126, 2014.

[11] WHO (World Health Organization), WHO Laboratory Manual for the Examination and Processing of Human Semen, pp. 7-114, WHO Press, Geneva, Switzerland, 5th edition, 2010.

[12] R. Mahfouz, R. Sharma, A. Thiyagarajan et al., "Semen characteristics and sperm DNA fragmentation in infertile men with low and high levels of seminal reactive oxygen species," Fertility and Sterility, vol. 94, no. 6, pp. 2141-2146, 2010.

[13] A. Aghazarian, I. Stancik, H. Pfluger, and J. Lackner, "Influence of pathogens and moderate leucocytes on seminal interleukin (IL)-6, IL-8, and sperm parameters," International Urology and Nephrology, vol. 45, no. 2, pp. 359-365, 2013.

[14] H. Umehara, E. T. Bloom, T. Okazaki, Y. Nagano, O. Yoshie, and T. Imai, "Fractalkine in vascular biology: from basic research to clinical disease," Arteriosclerosis, Thrombosis, and Vascular Biology, vol. 24, no. 1, pp. 34-40, 2004.

[15] V. Bjerkeli, J. K Damås, B. Fevang, J. C. Holter, P. Aukrust, and S. S. Frøland, "Increased expression of fractalkine (CX3CL1) and its receptor, CX3CR1, in Wegener's granulomatosispossible role in vascular inflammation," Rheumatology, vol. 46, no. 9, pp. 1422-1427, 2007.

[16] Q. Zhang, K. Shimoya, Y. Ohta et al., "Detection of fractalkine in human seminal plasma and its role in infertile patients," Human Reproduction, vol. 17, no. 6, pp. 1560-1564, 2002.

[17] A. Bahat, I. Tur-Kaspa, A. Gakamsky, L. C. Giojalas, H. Breitbart, and M. Eisenbach, "Thermotaxis of mammalian sperm cells: a potential navigation mechanism in the female genital tract," Nature Medicine, vol. 9, no. 2, pp. 149-150, 2003.

[18] M. Spehr, G. Gisselmann, A. Poplawski et al., "Identification of a testicular odorant receptor mediating human sperm chemotaxis," Science, vol. 299, no. 5615, pp. 2054-2058, 2003.

[19] Q. Zhang, K. Shimoya, K. Temma et al., "Expression of fractalkine in the Fallopian tube and of CX3CR1 in sperm," Human Reproduction, vol. 19, no. 2, pp. 409-414, 2004.

[20] M. Sarteschi, R. Paoli, M. Bianchini, and G. F. Menchini Fabris, "Lo studio del varicocele con eco-color-Doppler," Giornale Italiano di Ultrasonologia, vol. 4, pp. 43-49, 1993.

[21] ACR-AIUM-SIU, Practice Guideline for the Performance of Scrotal Ultrasound, Examination, Resolution, vol. 33, 2010, http://www. acr.org/ /media/ACR/Documents/PGTS/guidelines/US_Scrotal.pdf.

[22] Società Italiana di Diagnostica vascolare SIDV-GIUV, Procedure Operative Per Indagini Diagnostiche Vascolari, 2012, http://www.sidv.net/file_doc/GIUV\%2023-24.pdf.
[23] J. A. Politch, L. Tucker, F. P. Bowman, and D. J. Anderson, "Concentrations and significance of cytokines and other immunologic factors in semen of healthy fertile men," Human Reproduction, vol. 22, no. 11, pp. 2928-2935, 2007.

[24] A. W. Endtz, "A rapid staining method for differentiating granulocytes from "germinal cells" in Papanicolaou-stained semen,” Acta Cytologica, vol. 18, pp. 2-7, 1974.

[25] S. Aquila, M. Gentile, E. Middea, S. Catalano, and S. Andò, "Autocrine regulation of insulin secretion in human ejaculated spermatozoa," Endocrinology, vol. 146, no. 2, pp. 552557, 2005.

[26] P. T. Daniel, I. Sturm, S. Ritschel et al., "Detection of genomic DNA fragmentation during apoptosis (DNA ladder) and the simultaneous isolation of RNA from low cell numbers," Analytical Biochemistry, vol. 266, no. 1, pp. 110-115, 1999.

[27] H. H. Draper, E. J. Squires, H. Mahmoodi, J. Wu, S. Agarwal, and M. Hadley, "A comparative evaluation of thiobarbituric acid methods for the determination of malondialdehyde in biological materials," Free Radical Biology and Medicine, vol. 15, no. 4, pp. 353-363, 1993.

[28] C. Rice-Evans and N. J. Miller, "Total antioxidant status in plasma and body fluids," Methods in Enzymology, vol. 234, pp. 279-293, 1994.

[29] P. Pathak, A. Chandrashekar, T. S. Hakky, and A. W. Pastuszak, "Varicocele management in the era of in vitro fertilization/ intracytoplasmic sperm injection," Asian Journal of Andrology, vol. 18, no. 3, pp. 343-348, 2016.

[30] A. E. Zümrütbaş, Ö. Gülpınar, M. Mermerkaya, E. Süer, and Ö. Yaman, "The effect of varicocele on sperm morphology and DNA maturity: does acridine orange staining facilitate diagnosis?," Turkish Journal of Urology, vol. 39, no. 3, pp. 165-169, 2013.

[31] C.-L. Cho, S. C. Esteves, and A. Agarwal, "Novel insights into the pathophysiology of varicocele and its association with reactive oxygen species and sperm DNA fragmentation," Asian Journal of Andrology, vol. 18, no. 2, pp. 186-193, 2016.

[32] A. Agarwal, A. Hamada, and S. C. Esteves, "Insight into oxidative stress in varicocele-associated male infertility: part 1," Nature Reviews Urology, vol. 9, no. 12, pp. 678-690, 2012.

[33] R. J. Aitken and A. J. Koppers, "Apoptosis and DNA damage in human spermatozoa," Asian Journal of Andrology, vol. 13, no. 1, pp. 36-42, 2011.

[34] A. Zini and G. Dohle, "Are varicoceles associated with increased deoxyribonucleic acid fragmentation?," Fertility and Sterility, vol. 96, no. 6, pp. 1283-1287, 2011.

[35] R. J. Aitken, G. N. De Iuliis, and R. I. McLachlan, "Biological and clinical significance of DNA damage in the male germ line," International Journal of Andrology, vol. 32, no. 1, pp. 46-56, 2009.

[36] D. P. Evenson and R. Wixon, "Data analysis of two in vivo fertility studies using sperm chromatin structure assay-derived DNA fragmentation index vs. pregnancy outcome," Fertility and Sterility, vol. 90, no. 4, pp. 1229-1231, 2008.

[37] R. Henkel, E. Kierspel, T. Stalf et al., "Effect of reactive oxygen species produced by spermatozoa and leucocytes on sperm functions in non-leukocytospermic patients," Fertility and Sterility, vol. 83, no. 3, pp. 635-642, 2005.

[38] P. Piomboni, L. Gambera, F. Serafini, G. Campanella, G. Morgante, and V. De Leo, "Sperm quality improvement after natural anti-oxidant treatment of asthenoteratospermic men with leukocytospermia," Asian Journal of Andrology, vol. 10, no. 2, pp. 201-206, 2008. 
[39] S. Alshahrani, A. Agarwal, M. Assidi et al., "Infertile men older than 40 years are at higher risk of sperm DNA damage," Reproductive Biology and Endocrinology, vol. 12, no. 1, p. 103, 2014.

[40] M. Spano, J. P. Bonde, H. I. Hjollund, H. A. Kolstad, E. Cordelli, and G. Leter, "Sperm chromatin damage impairs human fertility. The Danish First Pregnancy Planner Study Team," Fertility and Sterility, vol. 73, no. 1, pp. 43-50, 2000.

[41] S. E. M. Lewis and R. J. Aitken, "DNA damage to spermatozoa has impacts on fertilization and pregnancy," Cell and Tissue Reserach, vol. 322, no. 1, pp. 33-41, 2005.

[42] M. Eisenberg and L. I. Lipshultz, "Varicocele-induced infertility: newer insights into its pathophysiology," Indian Journal of Urology, vol. 27, no. 1, pp. 58-64, 2011.

[43] M. Razi and H. Malekinejad, "Varicocele-induced infertility in animal models," International Journal of Fertility \& Sterility, vol. 9, no. 2, pp. 141-149, 2015.

[44] O. Celik, O. Kutlu, M. Tekcan, C. Celik-Ozenci, and I. Koksal, "Role of TNF-related apoptosis-inducing ligand (TRAIL) in the pathogenesis of varicocele-induced testicular dysfunction," Asian Journal of Andrology, vol. 15, no. 2, pp. 269-274, 2013.

[45] B. Habibi, B. Seifi, S. M.-H. N. Mougahi, M. Ojaghi, and H. R. Sadeghipour, "Increases in interleukin-6 and interferon-gamma levels is progressive in immature rats with varicocele," Irish Journal of Medical Science, vol. 184, no. 2, pp. 531-537, 2015.

[46] M. Zeinali, A. Hadian Ameree, H. Khorramdelazad, H. Karami, and M. Abedinzadeh, "Inflammatory and antiinflammatory cytokines in the seminal plasma of infertile men suffering from varicocele," Andrologia, vol. 49, no. 6, p. e12685, 2016

[47] Y. S. Oh, N. H. Jo, J. K. Park, and M. C. Gye, "Changes in inflammatory cytokines accompany deregulation of claudin11, resulting in inter-sertoli tight junctions in varicocele rat testes," The Journal of Urology, vol. 196, no. 4, pp. 1303-1312, 2016. 


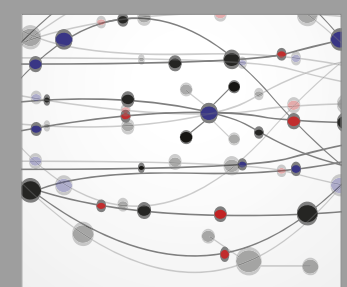

The Scientific World Journal
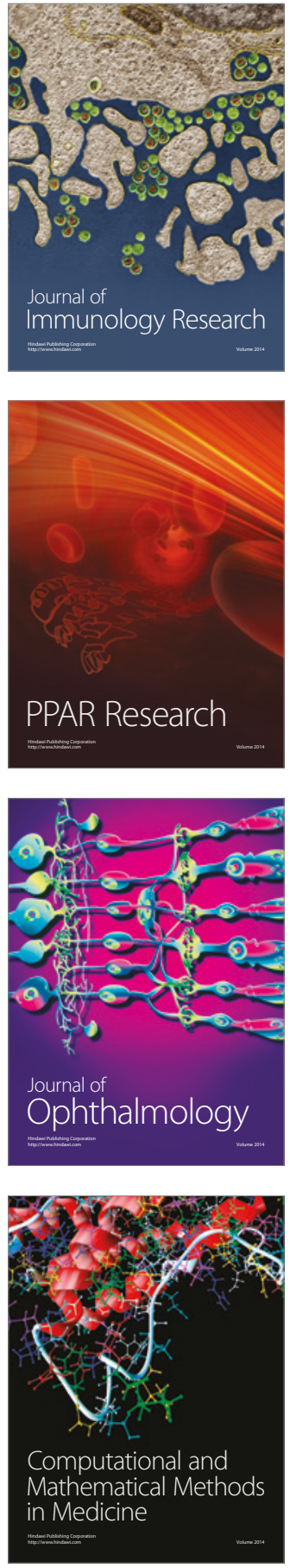

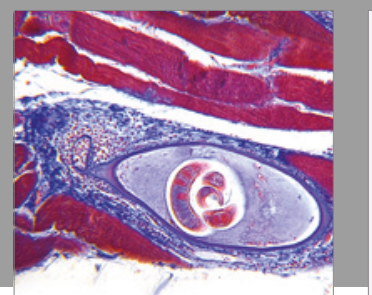

Gastroenterology Research and Practice
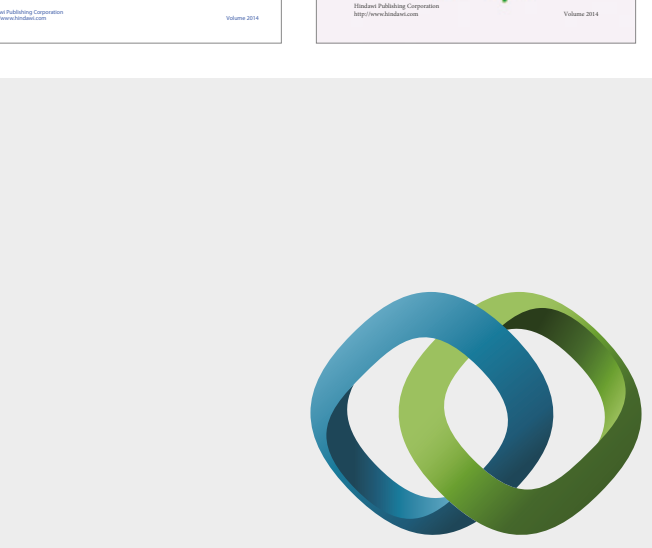

\section{Hindawi}

Submit your manuscripts at

https://www.hindawi.com
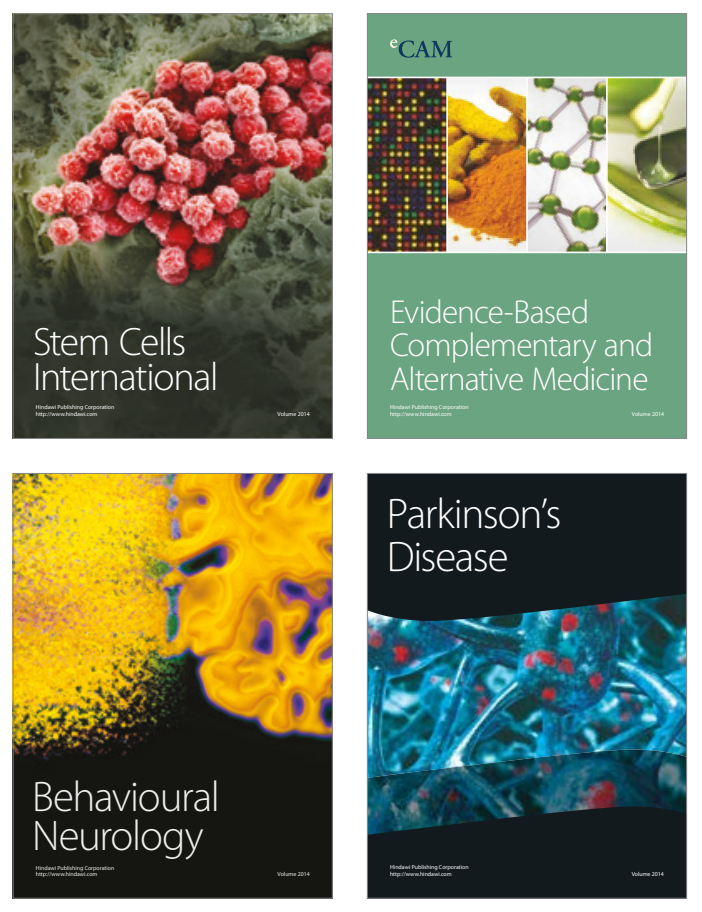
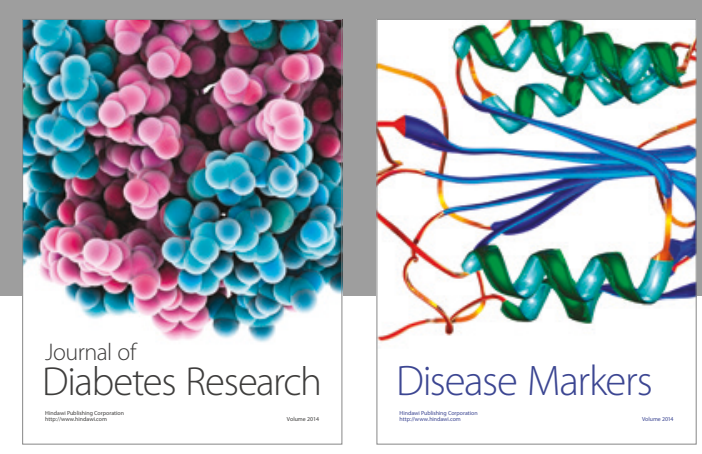

Disease Markers
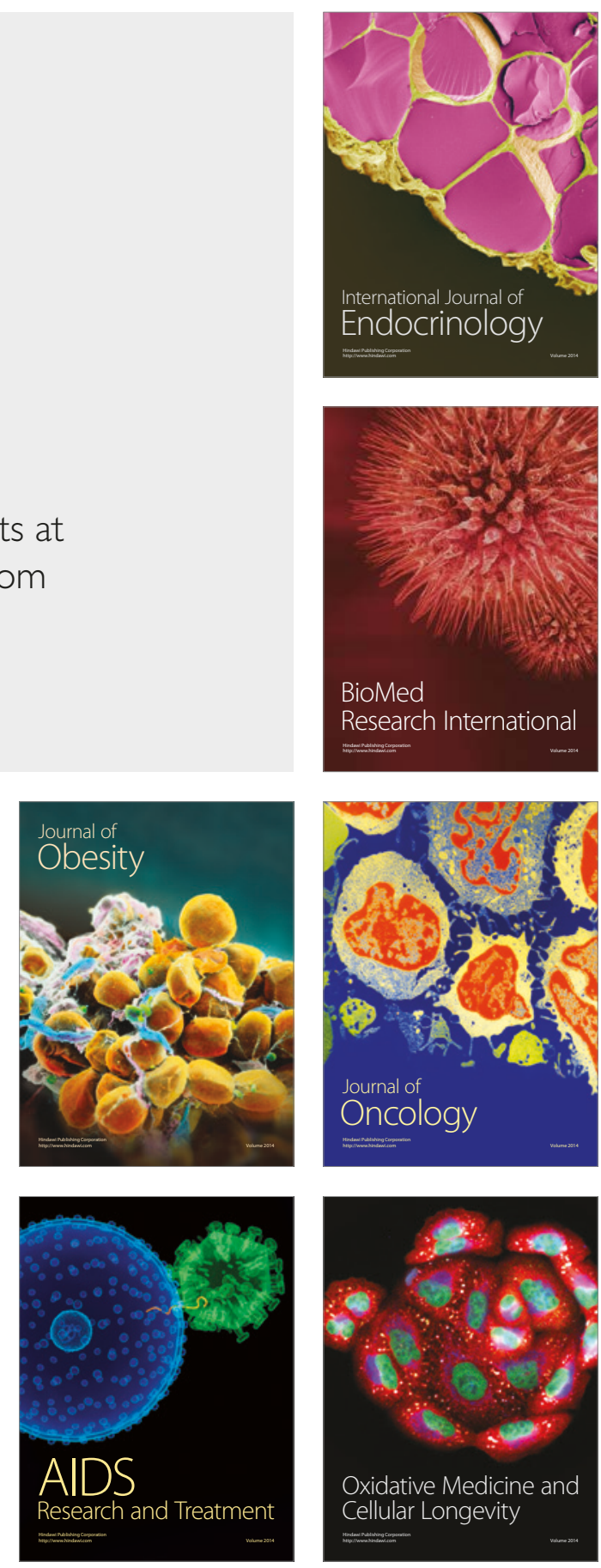